\title{
Prevalence, incidence and predictors of peripheral neuropathy in African adults with HIV infection within the DART trial
}

\author{
Sylvia Kiwuwa-Muyingo ${ }^{a}$, Bernard Kikaire ${ }^{a}$, Ivan Mambule ${ }^{b}$, \\ Helen Musana ${ }^{c}$, Godfrey Musorod , Charles F. Gilks ${ }^{\mathrm{e}}$, \\ Jonathan B. Levin ${ }^{a}$ and Anne Sarah Walker ${ }^{\mathrm{f}}$
}

Objectives: We investigated the prevalence, incidence and predictors of new peripheral neuropathy episodes in previously untreated, symptomatic HIV-infected Ugandan/Zimbabwean adults initiating zidovudine-based antiretroviral therapy (ART).

Design: An open-label, multicentre, randomized trial.

Methods: Peripheral neuropathy was self-reported at 12-weekly clinic visits. Cox regression models (excluding participants reporting preexisting peripheral neuropathy at ART initiation), considered sex; pre-ART WHO stage, age and $\mathrm{CD}^{+}$cell count; $\mathrm{CD} 4^{+}$cell count versus no $\mathrm{CD} 4^{+}$cell count monitoring; and time-updated $\mathrm{CD} 4^{+}$cell count, weight and use of stavudine, isoniazid and didanosine.

Results: Four hundred and twenty-one out of 3316(13\%) patients reported preexisting peripheral neuropathy at ART initiation. Median (interquartile range, IQR) follow-up in 2895 participants without preexisting peripheral neuropathy was $4.9(4.7-5.4)$ years. Three hundred and fifty-four (12\%) took stavudine as first-line substitution and 518 (18\%) took isoniazid during follow-up. Two hundred and ninety (11\%) participants developed a new peripheral neuropathy episode, an incidence of 2.12 per 100 personyears. Eighteen $(0.1 \%)$ had a grade $3 / 4$ episode. Independent predictors of peripheral neuropathy were current stavudine use [adjusted hazard ratio (a)HR 4.16 (95\% confidence interval, $95 \% \mathrm{Cl} 3.06-5.66$ ], current isoniazid use [aHR $1.59(95 \% \mathrm{Cl}$ $1.02-2.47)]$ and current didanosine use [aHR 1.60 (95\% Cl 1.19-2.14)]. Higher risks were independently associated with higher pre-ART weight [aHR (per+5 kg) 1.07 (95\% $\mathrm{Cl} 1.01-1.13)$ ] and older age aHR (per 10 years older) 1.29 (95\% Cl 1.12-1.49), but there was no significant effect of sex $(P=0.13)$, pre-ART CD4 ${ }^{+}$cell count $(P=0.91)$ or $\mathrm{CD} 4{ }^{+}$cell count monitoring $(P=0.73)$.

Conclusion: Current stavudine, didanosine or isoniazid use continue to increase peripheral neuropathy risks, as does older age and weight at ART initiation; however, we found no evidence of increased risk in women in contrast to previous studies. The incidence of peripheral neuropathy may now be lower in ART programmes, as stavudine and didanosine are no longer recommended. All patients receiving isoniazid, either as part of antituberculosis (TB) chemotherapy or TB-preventive therapy, should receive pyridoxine as recommended in national guidelines.

(c) 2014 Wolters Kluwer Health | Lippincott Williams \& Wilkins

AIDS 2014, 28:2579-2588

Keywords: Africa, antiretroviral therapy, clinical trials, didanosine, isoniazid, peripheral neuropathy, stavudine

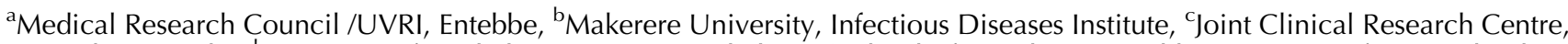
Kampala, Uganda, 'University of Zimbabwe, Harare, Zimbabwe, ${ }^{\mathrm{e} S}$ chool of Population Health, University of Queensland, Brisbane, Queensland, Australia, and ${ }^{\mathrm{f}}$ Medical Research Council Clinical Trials Unit at University College London, London, UK. Correspondence to Sylvia Kiwuwa-Muyingo, Medical Research Council/Uganda Virus Research Institute, P.O Box 49, Entebbe, Uganda.
}

Tel: +256 712529247; e-mail:Sylvia.muyingo@mrcuganda.org

Received: 16 June 2014; revised: 6 August 2014; accepted: 7 August 2014.

DOI:10.1097/QAD.0000000000000447

ISSN 0269-9370 ( 2014 Wolters Kluwer Health | Lippincott Williams \& Wilkins. This is an open access article distributed under the Creative Commons Attribution-Non Commercial License 4.0, where it is permissible to download, share and reproduce the work in any medium, provided it is properly cited. The work cannot be used commercially. 


\section{Introduction}

Peripheral neuropathy is the most common neurological disorder in people with HIV infection and is associated with both HIV disease and antiretroviral therapy (ART). In the pre-ARTera, peripheral neuropathy was associated with advanced HIV disease and severe immunosuppression [1]. The introduction of combination ART in high-income countries in the 1990s led to a reduction in overall incidence of neurological complications including peripheral neuropathy [2]. However, peripheral neuropathy is also a recognized adverse effect associated with the use of nucleoside analogue reverse transcriptase inhibitors such as stavudine and didanosine [3]. In resource-limited settings, stavudine in particular has been used more frequently in combination ART due to its low cost. However, both HIV and ART-associated peripheral neuropathy can coexist and it may be difficult to distinguish between them clinically. Additional factors such as older age, female sex, low $\mathrm{CD}^{+}$cell count, nutritional deficiencies, antituberculosis (anti-TB) drugs, high viral load, chemotherapy and alcohol use have been identified as risk factors for newly diagnosed peripheral neuropathy in previous studies [4-7].

Sensory neuropathies are the most common manifestation of peripheral neuropathy and are characterized by pain and abnormal sensations such as numbness, pricking or burning. Pain associated with peripheral neuropathy has been identified as a major source of discomfort (with a consequent impact on quality of life) and a limiting factor in patients remaining on and/or adhering to antiretroviral treatment [8]. Thus, peripheral neuropathy has the potential to increase rates of first-line failure and hence future treatment costs.

Screening tools for peripheral neuropathy have been developed including the Brief Peripheral Neuropathy Screen (BPNS) for reported symptoms, quantitative tests and/or clinical assessments administered by clinician or patients. However, these tools have been less frequently used in resource-limited settings. The few existing studies in sub-Saharan Africa have shown widely varying prevalence of $1-60 \%$ with HIV or ART-related peripheral neuropathy $[7,9-15]$. The post-ART incidence rates for peripheral neuropathy were also not consistent across several studies, varying between 0.9 and 40 per 100 person-years in a review [15]. The differences probably reflect varying definitions, different clinical settings, short follow-up time and the lack of a standard validated screening tool.

Although use of stavudine has now been phased out in most countries in sub-Saharan Africa following WHO guidelines, resource-limited settings still face challenges from peripheral neuropathy due to a high prevalence of other risk factors such as advanced HIV disease, burden of TB and malnutrition. To further understand the factors associated with peripheral neuropathy, and in particular to examine the independent risks associated with use of stavudine, didanosine and isoniazid, we carried out a secondary analysis of the data from the Development of Antiretroviral Therapy (DART) trial in Uganda and Zimbabwe.

\section{Materials and methods}

DART was an open, randomized controlled trial comparing two management strategies for monitoring ART: routine laboratory and clinical monitoring $\left(12\right.$-weekly $\mathrm{CD}^{+}{ }^{+}$cell count and haematology and biochemistry tests) versus clinically driven monitoring (haematology or biochemistry tests only if clinically indicated) [16]. Between September 2003 and October 2004, the trial enrolled 3316 symptomatic (WHO stage 2-4) HIV-infected ART-naive adults aged at least 18 years with $\mathrm{CD}^{+}{ }^{+}$cell counts less than $200 \mathrm{cell} \mathrm{s} / \mu \mathrm{l}$ in Uganda (two centres with one satellite) and Zimbabwe (one centre). At enrolment, all participants started tripledrug combination ART with zidovudine/lamuvidine along with either tenofovir (in 2003/2004) or nevirapine or abacavir (2004 only) following WHO guidelines at the time [17]. Stavudine was used as a first-line substitution and didanosine as part of second-line treatment according to WHO guidelines. A second randomization compared structured treatment interruptions with continuous ART in 813 participants until March 2006, when it was terminated and participants on structured treatment interruptions were moved to continuous ART [18].

Pre-ART clinical and demographic characteristics were recorded. All participants saw a doctor and had a routine full blood count with white cell differential and lymphocyte subsets at screening, weeks 4 and 12 and then every 12 weeks, although in the clinically driven monitoring arm, results were not returned to the trial doctors unless there was a grade 4 abnormality or if the results were requested for clinical reasons $\left(\mathrm{CD} 4^{+}\right.$cell counts were never returned). The doctor visit included specific elicitation of symptoms of peripheral neuropathy as a case record form (CRF) data item, and if present, clinical symptoms were described and graded as follows: grade 1 - mild paraesthesia, numbness, pain or weakness, not requiring treatment; grade 2 , moderate paraesthesia, numbness or pain, objective weakness, requiring analgesic; grade 3, severe paraesthesia, numbness or pain or weakness, interfering with normal activity, requiring a narcotic; grade 4, intolerable paraesthesia, numbness or pain resulting in incapacity, paralysis or being unable to walk, despite narcotics. There was no attempt made to distinguish HIV and ART-associated peripheral neuropathy symptoms. Other clinical events were also documented at follow-up visits. Participants' adherence to ART was assessed by pill counts and a structured 
questionnaire administered at each scheduled 4-weekly clinic visit. ART substitutions could be made for toxicity at the discretion of the treating physician, for example stavudine for zidovudine in the case of severe (grade 3-4) anaemia. Anti-TB drugs included isoniazid according to national guidelines on TB treatment, which also advocate the use of pyridoxine to lessen the risk of peripheral neuropathy.

\section{Statistical analysis}

Our aim was to characterize prevalence, cumulative incidence and predictors of new peripheral neuropathy episodes in previously untreated adults initiating ART; we therefore excluded all individuals reporting preexisting peripheral neuropathy at ART initiation from analyses. The primary outcome was time from ART initiation to first peripheral neuropathy episode, regardless of severity/grade, and censoring at the earliest of loss of follow-up, death or 31 December 2008 (end of trial). Potential demographic and clinical explanatory variables were summarized according to whether or not the participant ever experienced an episode of peripheral neuropathy, using frequencies and percentages for categorical variables, and means and standard deviations or medians and inter-quartile ranges for continuous variables.

The Kaplan-Meier method was used to estimate the incidence of peripheral neuropathy, with Cox models used to assess the following pre-ART risk factors: age (18-35, 35-50, more than 50 years), sex (male, female), WHO disease stage [2-4], weight and $\mathrm{CD}^{+}$cell count. Following a reviewer's suggestion, we further assessed whether pre-ART height was a risk factor for the development of peripheral neuropathy. We investigated nonlinearity of continuous $\mathrm{CD} 4^{+}$cell count, weight and age using fractional polynomials regression [19]. We fitted univariable and multivariable models selecting by backward elimination (exit probability of 0.1 ). In separate time-dependent Cox models, we then also considered the impact of time-updated factors, $\mathrm{CD} 4^{+}$cell count, weight, stavudine use, isoniazid use and didanosine use, adjusted for main DART randomized monitoring strategy and preART factors found to be independent predictors in the model for pre-ART factors above. Isoniazid was included as both a two-level variable (current use vs. no current use) and a three-level variable with levels no use, isoniazid with pyridoxine and isoniazid without pyridoxine. We further summarized the history of isoniazid use as a four-level variable: never used; current use; last used 0-90 days ago; and last used more than 90 days ago. Statistical analysis was performed using Stata version 12 (Stata Corp., College Station, Texas, USA) and R version 2.15.1.

\section{Results}

\section{Characteristics of study population by peripheral neuropathy status}

Three thousand three hundred and sixteen patients were enrolled in the DART trial between January 2003 and October 2004. Four hundred and twenty-one (13\%) reported preexisting peripheral neuropathy at ART initiation leaving 2895 participants in this analysis with a median (interquartile range, IQR) 4.9 (4.7-5.4) years follow-up after ART initiation. All participants initiated ART with zidovudine/lamivudine coformulated as combivir and either tenofovir 2200 (76\%), nevirapine $457(16 \%)$ or abacavir $238(8 \%)$. Three hundred and fiftyfour $(12 \%)$ took stavudine, $518(18 \%)$ took isoniazid and 396 (14\%) took didanosine during follow-up. Pyridoxine (vitamin B complex) was prescribed along with isoniazid used as TB treatment or prophylaxis in 228 (44\%) of those taking isoniazid. Overall, 290 (11\%) participants developed a new peripheral neuropathy episode on ART; $67 \%$ were women, median age was 37 years and median (IQR) pre-ART $\mathrm{CD}^{+}$cell count was 82 cells $/ \mu 1$ $(34-133$ cells $/ \mu \mathrm{l})$, see Table 1 . One hundred and

Table 1. Pre-antiretroviral therapy characteristics associated with cumulative incidence of peripheral neuropathy.

Cumulative incidence of PN

Present $n=290(100 \%)$

Absent $n=2605(100 \%)$

Preexisting $n=421(100 \%)$

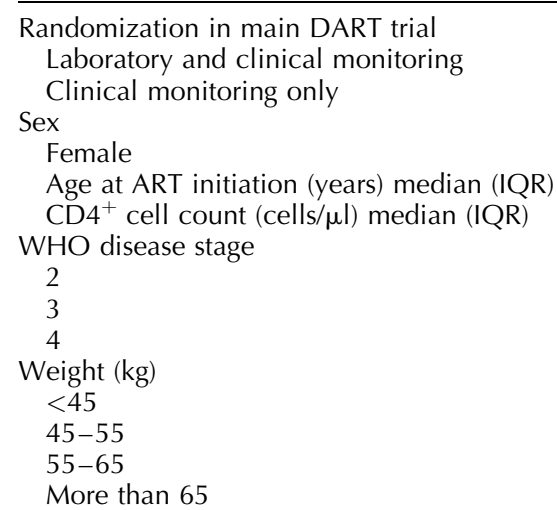

$150(52 \%)$
$140(48 \%)$

$193(67 \%)$
$37(33-43)$
$82(34-133)$
$50(17 \%)$
$171(59 \%)$
$69(59 \%)$
$21(7 \%)$
$93(32 \%)$
$98(34 \%)$
$77(27 \%)$

$1299(50 \%)$
$1306(50 \%)$
$1697(65 \%)$
$36(31-42)$
$88(33-142)$

$567(22 \%)$
$1458(56 \%)$
$580(22 \%)$
$264(10 \%)$
$913(35 \%)$
$899(35 \%)$
$510(20 \%)$

$207(49 \%)$

$214(51 \%)$

$266(63 \%)$

$39(34-43)$

$90(33-136)$

$56(13 \%)$

$235(56 \%)$

$130(31 \%)$

$34(8 \%)$

$136(32 \%)$

$151(36 \%)$

$97(23 \%)$

ART, antiretroviral therapy; IQR, interquartile range; $\mathrm{PN}$, peripheral neuropathy. 
thirty-four (7\%) participants developed a new peripheral neuropathy episode exclusively on a zidovudine-based regimen, that is without ever receiving stavudine or didanosine; 21 out of 134 had received isoniazid.

\section{Cumulative incidence of peripheral neuropathy over time}

Of 290 participants developing new peripheral neuropathy episodes on ART, 118 (41\%) had at most grade 1 peripheral neuropathy (including 16 participants with no grade ever reported), $154(53 \%)$ at most grade 2 peripheral neuropathy and $18(6 \%)$ reported grade 3 or 4 peripheral neuropathy at some point during follow-up. Nine out of 18 grade 3/4 peripheral neuropathy events occurred by 96 weeks. The overall incidence of any grade peripheral neuropathy was 2.12 per 100 person-years $(0.10 / 100$ person-years for grade $3 / 4)$ and was greater in the first year on ART $(P<0.001)$. Kaplan-Meier plots showing the time to first post-ART episode of peripheral neuropathy are shown in Fig. 1, broken down by age and weight at ART initiation. In time-dependent analyses, the rates were higher for participants who ever used stavudine, for participants who ever used didanosine and for participants who ever used isoniazid, particularly if they were not recorded as having taken concomitant pyridoxine (Table 2), which was given as $25 \mathrm{mg}$ /day according to national guidelines. Prevalence of peripheral neuropathy during follow-up at 6 months and 1, 2, 3, 4, 5,6 years was $0.7,0.7,0.4,0.4,0.1,0.5$ and 0.5 , respectively, Fig. 2.

\section{Pre-antiretroviral therapy risk factors for development of peripheral neuropathy on antiretroviral therapy}

The results of the unadjusted and adjusted Cox regression models are summarized in Table 3. Independently, older age at ART initiation [adjusted hazard ratio, aHR, 1.25 per 10 year older, 95\% confidence interval (95\% CI) 1.091.45] and increasing weight at ART initiation (aHR 1.06 per $5 \mathrm{~kg}$ heavier, $95 \% \mathrm{CI} 1.01-1.12$ ) significantly increased the risk of peripheral neuropathy on ART. There was no evidence of an effect of sex, height, WHO stage or CD4 ${ }^{+}$ cell count at ART initiation, or of randomized $\mathrm{CD} 4^{+}$cell count monitoring strategy $(P>0.2)$.

\section{Time-updated factors associated with development of peripheral neuropathy}

Independently in the time-updated model (Table 3), current use of stavudine (aHR 4.16, 95\% CI 3.06-5.66); current use of isoniazid (aHR 1.57, 95\% CI 1.00-2.44); and current use of didanosine (aHR 1.60, 95\% CI 1.192.14) increased the risk of developing peripheral neuropathy. Investigating effect modification by concurrent use of pyridoxine, in a multivariable sensitivity analysis, we found a lower risk of peripheral neuropathy associated with current use of isoniazid with pyridoxine (aHR 1.23, 95\% CI 0.46-3.32) than isoniazid without pyridoxine (aHR 1.67, 95\% CI 1.02-2.71) but nor were there sufficient events to determine whether or not this risk really differed (heterogeneity $P=0.59$ ). Even after adjusting for these time-dependent factors, greater peripheral neuropathy risks associated with older age and heavier weight at ART initiation remained $(P \leq 0.001$, Table 3$)$. After adjusting for these preART factors, and time-updated stavudine, didanosine and isoniazid use, there was no evidence that the risk of peripheral neuropathy depended on sex (aHR 1.07, 95\% CI 0.77-1.49), time-updated $\mathrm{CD}^{+}$cell count (aHR 1.01 per $100 \mathrm{cells} / \mu \mathrm{l}$ higher, 95\% CI $0.82-1.24)$ or randomized $\mathrm{CD}^{+}{ }^{+}$cell count monitoring strategy (aHR 0.95, 95\% CI 0.76-1.20), height per $\mathrm{cm}$ higher (aHR $0.99,95 \%$ CI $0.97-1.01)$. In a further sensitivity analysis, we also considered previous isoniazid use: compared with never having used isoniazid, the risk of peripheral neuropathy tended to be higher for current isoniazid use (adjusted for other factors in the time-updated multivariable model in Table 3 aHR 1.54, 95\% CI 0.99-2.40) than last use within the prior $0-90$ days (aHR 0.27, 95\% CI $0.04-1.90$ ) or more than 90 days previously (aHR $0.88,95 \%$ CI 0.55-1.41). However, the numbers developing peripheral neuropathy in the latter two groups (1 and 21 events, respectively) were few, and there was no formal evidence for variation in peripheral neuropathy risk according to time since last isoniazid use (heterogeneity $P=0.07$ ).

\section{Discussion}

The results from this large cohort of HIV-infected individuals initiating ART with zidovudine-based regimens in sub-Saharan Africa demonstrate that use of isoniazid, didanosine, stavudine as well as higher preART weight and greater age are the key risk factors for development of new peripheral neuropathy on ART; however, we found no evidence of increased risk in women in contrast to previous studies. Further, risks of peripheral neuropathy appear to be increased even if pyridoxine is given with isoniazid as per national guidelines. A systematic review of 48 studies (including randomized trials) concluded that it was unclear whether or not use of pyridoxine with isoniazid decreases peripheral neuropathy risk [20]. A further issue is that pyridoxine dosing recommendations differ in different countries and may also impact peripheral neuropathy risk: however, in Uganda and Zimbabwe, $25 \mathrm{mg} /$ day is the recommended dose in national guidelines. Actual dose was not recorded on trial CRFs, so we are unable to investigate the impact of dose further. Clinicians may recommend a variety of nutritional supplements including vitamin $\mathrm{B}$, but data supporting their use in prevention or treatment of peripheral neuropathy remain sparse [21]. We did not collect data on nutritional supplements so cannot assess this Vitamin B6 toxicity due to additional nutritional supplements or other dietary intake of natural 
(a)

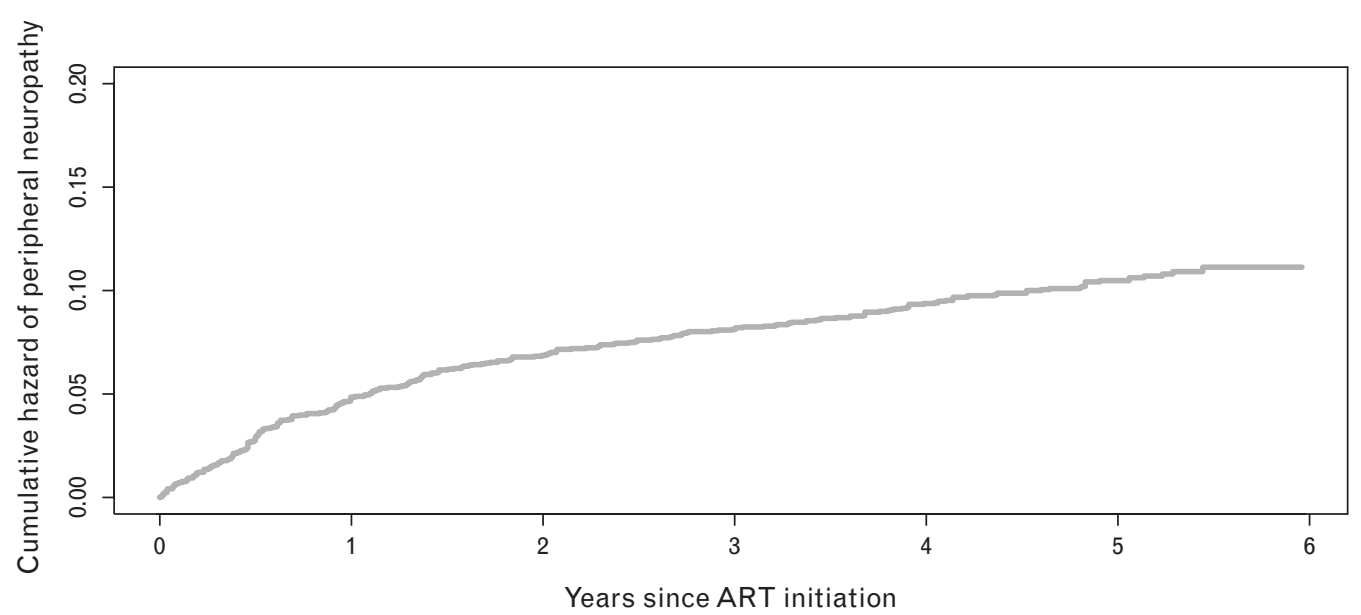

(b)

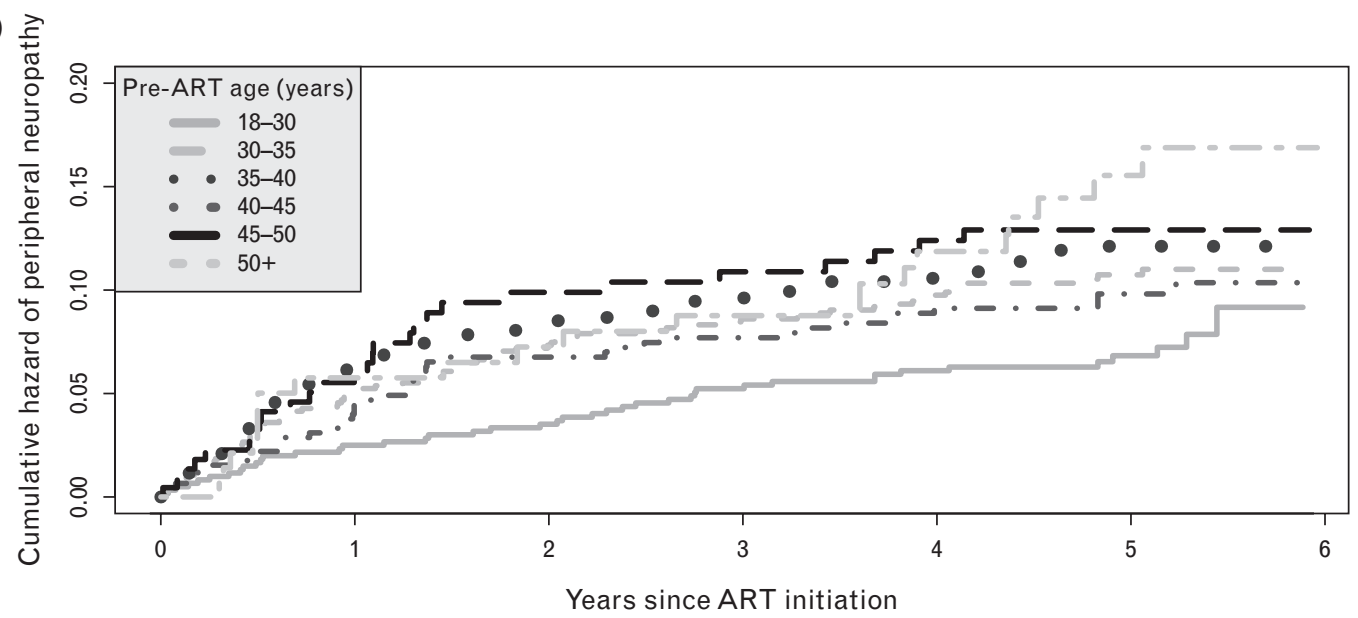

(c)

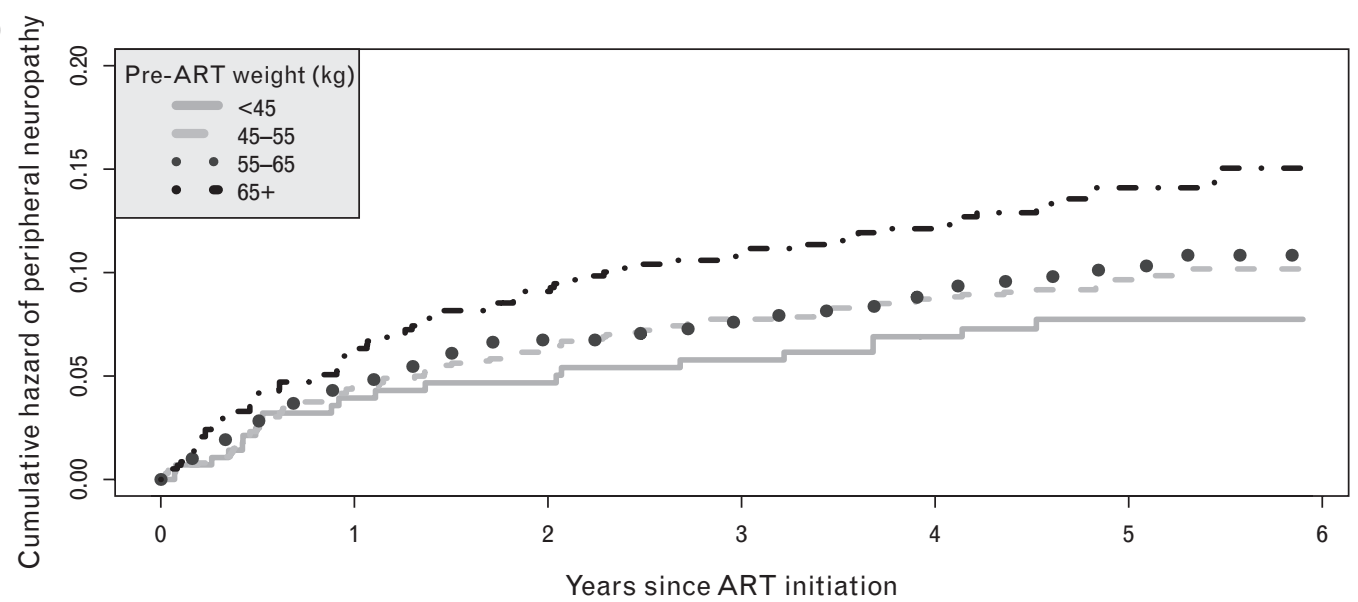

Fig. 1. Cumulative hazard of 2895 participants over time from antiretroviral therapy initiation. (a) Overall, (b) stratified by age and (c) stratified by weight.

food sources of vitamins, such as nuts, could theoretically cause neuropathic pain. This toxicity is unlikely to have occurred in our study, as vitamin B6 intake was likely inadequate, for example nutritional supplements would have been limited due to cost and access and most nuts are often processed resulting in loss of some nutrients; however, it might be considered in other settings.

We found, as has been shown in other studies, that stavudine significantly increased the risk of peripheral 
Table 2. Peripheral neuropathy event rate by exposure to specific drugs.

\begin{tabular}{|c|c|c|c|c|}
\hline Factor & & $N(\%)$ ever used & Events $N=290$ & $\begin{array}{c}\text { Event rate per } 100 \\
\text { person-years }(95 \% \mathrm{Cl})\end{array}$ \\
\hline \multirow[t]{2}{*}{ Current use of stavudine } & No & & 235 & $1.8(1.6-2.1)$ \\
\hline & Yes & $354(12 \%)$ & 55 & $5.8(4.5-7.6)$ \\
\hline \multirow{2}{*}{ Current use of didanosine } & No & & 233 & $2.0(1.7-2.2)$ \\
\hline & Yes & $396(14 \%)$ & 57 & $3.1(2.4-4.0)$ \\
\hline \multirow[t]{3}{*}{ Current use of isoniazid } & Yes with pyridoxine & $153(5 \%)$ & 4 & $3.5(1.4-8.3)$ \\
\hline & Yes without pyridoxine & $365(13 \%)$ & 18 & $4.6(2.9-7.4)$ \\
\hline & No & & 263 & $2.0(1.8-2.3)$ \\
\hline \multirow[t]{2}{*}{ Current use of isoniazid } & No & & 267 & $2.0(1.8-2.3)$ \\
\hline & Yes & $518(18 \%)$ & 23 & $4.3(2.9-6.5)$ \\
\hline \multirow{4}{*}{ Use of isoniazid } & No & & 245 & $2.1(1.9-2.4)$ \\
\hline & Current use & $518(18 \%)$ & 23 & $4.3(2.9-6.5)$ \\
\hline & Used in the last $0-90$ days & & 1 & $1.0(0.1-5.7)$ \\
\hline & Last used $>90$ days ago & & 21 & $1.5(1.0-2.3)$ \\
\hline
\end{tabular}

$\mathrm{Cl}$, confidence interval.

neuropathy $[9,10,22-24]$. The association of didanosine with peripheral neuropathy is also consistent with previous studies from high-income countries [5]. However, not all studies have found higher rates of peripheral neuropathy in those receiving didanosine, for example Moore et al. [3] found peripheral neuropathy to be associated with combined use of didanosine and stavudine but not didanosine alone, and Kelleher et al. [25] found no association of didanosine with peripheral neuropathy in a clinical trial using higher didanosine doses than now recommended.

Post-ART prevalence in resource-limited settings from previous studies has been estimated between 20 and $50 \%$ [13-15] but with a wide variation noted in a previous systematic review [15]. Thirteen percent of the DART trial population reported preexisting peripheral neuropathy at ART initiation, which is lower than the

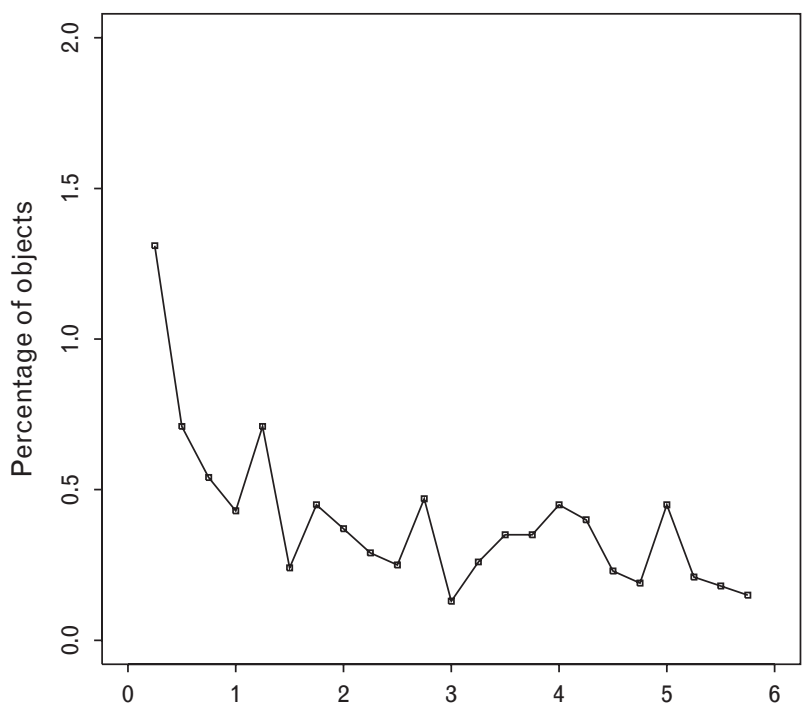

Fig. 2. Prevalence of peripheral neuropathy in participants not reporting peripheral neuropathy (any grade) at enrolment over time from antiretroviral therapy initiation.
post-ART peripheral neuropathy prevalence from previous studies, which however highlights the importance of nondrug-based factors. On ART, prevalence in those not reporting preexisting peripheral neuropathy at ART initiation was nearly $1 \%$ at subsequent follow-up visits. Overall, pre-ART prevalence is more similar to studies from high-income settings $[3,24,26]$ and one study in Asia [27], and lower than other studies from resource-limited settings $[7,9,23,28]$ for reasons that are unclear. The differences in on-ART prevalence estimates may be due to a high proportion of stavudine use in other ART programmes in resource-limited settings, whereas this was only used as a first-line substitution in DART. Although less use of stavudine may explain at least some of this difference, $7 \%$ of those initiating ART and never receiving stavudine or didanosine during follow-up developed peripheral neuropathy compared with $20 \%$ using zidovudine-based regimens in Shurie and Deribew [28]; assessment methods for peripheral neuropathy could therefore also play a role. Importantly, most new episodes on ART were mild/moderate and severe peripheral neuropathy was rare in this study. The incidence of peripheral neuropathy should now be lower in the general HIV-infected population, as stavudine is no longer recommended even as a first-line substitution in the most recent WHO guidelines [29], nor is didanosine recommended in second-line.

The incidence of peripheral neuropathy in our study was higher in the first year on ART than subsequently, with an incidence less than $1 \%$ per annum after the first year on ART. Our findings are similar to other studies in highincome settings showing that the risk of peripheral neuropathy is relatively low after the first 6-12 months on ART. For example, in the Delta trial, the estimated incidence rate of peripheral neuropathy peaked in first 90 days and then declined [30]; Lichtenstein et al. [31] also observed higher peripheral neuropathy incidence in first 6 months on ART, which subsequently dropped and then remained low with increasing time on ART, even in severely immunosuppressed HIV-infected individuals. 
Table 3. Baseline and time-updated predictors of peripheral neuropathy in 2895 persons not reporting peripheral neuropathy at antiretroviral therapy initiation.

\begin{tabular}{|c|c|c|c|c|c|c|c|c|c|}
\hline & \multicolumn{3}{|c|}{ Univariable models } & \multicolumn{3}{|c|}{$\begin{array}{l}\text { Multivariable model } \\
\text { including pre-ART } \\
\text { factors only }{ }^{\mathrm{a}}\end{array}$} & \multicolumn{3}{|c|}{$\begin{array}{l}\text { Multivariable model } \\
\text { including time-updated } \\
\text { factors }^{\text {a }}\end{array}$} \\
\hline & $\begin{array}{l}\text { Unadjusted } \\
\text { HR }\end{array}$ & $95 \% \mathrm{Cl}$ & $P$ & $\begin{array}{l}\text { Adjusted } \\
\text { HR }\end{array}$ & $95 \% \mathrm{Cl}$ & $P$ & $\begin{array}{l}\text { Adjusted } \\
\text { HR }\end{array}$ & $95 \% \mathrm{Cl}$ & $P$ \\
\hline Female vs. male & 1.06 & $(0.83-1.35)$ & 0.6 & & & & & & \\
\hline Age (per 10 years older) & 1.27 & $(1.11-1.47)$ & 0.001 & 1.25 & $(1.09-1.45)$ & 0.002 & 1.29 & $(1.12-1.49)$ & $<0.001$ \\
\hline \multicolumn{10}{|l|}{ WHO stage } \\
\hline Stage 2 & 0.76 & $(0.55-2.02)$ & & & & & & & \\
\hline Stage 3 & 1 (ref) & - & 0.2 & & & & & & \\
\hline Stage 4 & 1.00 & $(0.76-1.33)$ & & & & & & & \\
\hline $\begin{array}{l}\text { Pre-ART CD4 }{ }^{+} \text {cell count } \\
(\text { per } 100 \text { cells/ } \mu l \text { higher })\end{array}$ & 0.94 & $(0.77-1.14)$ & 0.5 & & & & & & \\
\hline \multicolumn{10}{|l|}{ Pre-ART weight } \\
\hline $\begin{array}{l}\text { No } \mathrm{CD}^{+} \text {vs. }^{\mathrm{CD}} 4^{+} \text {cell } \\
\text { count monitoring }\end{array}$ & 0.93 & $(0.74-1.18)$ & 0.6 & & & & & & \\
\hline $\begin{array}{l}\text { Current CD4 }{ }^{+} \text {cell count } \\
\quad(\text { per } 100 \text { cells } / \mu \text { l higher })\end{array}$ & 0.93 & $(0.76-1.12)$ & 0.4 & & & & & & \\
\hline \multicolumn{10}{|l|}{ Currently on stavudine } \\
\hline Yes vs. no & 3.82 & $(2.82-5.17)$ & $<0.001$ & & & & 4.16 & $(3.06-5.66)$ & $<0.001$ \\
\hline $\begin{array}{l}\text { Currently on isoniazid } \\
\text { Isoniazid: sensitivity analysis }\end{array}$ & 1.75 & $(1.12-2.72)$ & 0.01 & & & & 1.57 & $(1.00-2.44)$ & 0.05 \\
\hline Not on isoniazid & 1 (ref) & & $0.04^{\mathrm{b}}$ & & & & 1 (ref) & & $0.11^{\mathrm{c}}$ \\
\hline Isoniazid with pyridoxine & 1.46 & $(0.54-3.92)$ & 0.46 & & & & 1.23 & $(0.46-3.32)$ & 0.68 \\
\hline Isoniazid without pyridoxine & 1.83 & $(1.13-2.97)$ & 0.02 & & & & 1.67 & $(1.02-2.71)$ & 0.04 \\
\hline \multicolumn{10}{|l|}{ Currently on didanosine } \\
\hline Yes vs. no & 1.51 & $(1.12-2.02)$ & 0.01 & & & & 1.60 & $(1.19-2.14)$ & 0.002 \\
\hline Pre-ART height per $\mathrm{cm}$ higher & 1.00 & $(0.98-1.01)$ & 0.6 & & & & 0.99 & $(0.97-1.01)$ & 0.2 \\
\hline
\end{tabular}

There was no evidence of nonlinearity in the effect of any continuous factors tested using fractional polynomials $(P>0.05)$. ART, antiretroviral therapy; $\mathrm{Cl}$, confidence interval; $\mathrm{HR}$, hazard ratio; $\mathrm{PN}$, peripheral neuropathy.

a Backwards elimination (exit $P=0.1$ ); time-updated models used factors that independently predicted PN in the pre-ART model.

${ }^{\mathrm{b}} \mathrm{Global}(2 \mathrm{df}) P=0.04$; test for heterogeneity of effect of isoniazid according to concomitant use of pyridoxine or not $P=0.68$.

${ }^{\mathrm{c}} \mathrm{Global}$ (2df) $P=0.11$; test for heterogeneity of effect of isoniazid according to concomitant use of pyridoxine or not $P=0.59$.

However, as above, overall, we observed a lower postART peripheral neuropathy incidence than more recent studies in Africa [22,23,32,33] and one USA study [34].

In our study, pre-ART age and weight were independent risk factors for peripheral neuropathy, whether or not time-updated drug exposure was also adjusted for. Previous studies have shown peripheral neuropathy associations with age consistently [35-37] and also with either weight or BMI; we observed higher peripheral neuropathy risk in heavier individuals comparable to previous studies [10,38]. Models including pre-ART BMI rather than weight gave similar inferences in our data (not shown). The association of peripheral neuropathy with pre-ART weight may be explained by poor peripheral nerve distribution in the fat beneath the skin among overweight individuals. Previous studies have shown that greater height increases the risk of peripheral neuropathy [39]. This result is not replicated in our study, but the significant association of BMI with risk of peripheral neuropathy development is probably indicative of the impact of weight. In contrast to our study, previous studies have also found associations between peripheral neuropathy and sex $[33,39,40]$ and pre-ART $\mathrm{CD}^{+}$or time-updated $\mathrm{CD}^{+}$cell count $[3,30]$. For example,
Mehta et al. [33] found that women were 10 times more likely to develop peripheral neuropathy in the first year on ART in a Kenyan cohort (63\% initiating stavudine-based regimens), an association that persisted after adjustment for age, pre-ART BMI and initial stavudine. The BPNS used in this Kenyan study combines patient assessment of symptoms with clinical assessment of vibration sense and ankle deep tendon reflexes; one explanation for the significantly higher rates in women could have been greater reporting of symptoms. Currier et al. [41] also showed that women more often discontinued ART due to adverse events including peripheral neuropathy more frequently than men. Previous associations between peripheral neuropathy and $\mathrm{CD} 4^{+}$cell count are from the precombination ART era: the lack of association in our study support the findings by Wadley et al. [10] that suggest $\mathrm{CD}^{+}$cell count may be a less important predictor in the context of combination ART.

Most peripheral neuropathy events observed were mild; it is unlikely that we would have missed severe cases. One question is how these generally mild cases are best managed. Novel therapies may be of limited efficacy and are often unavailable in resource-limited settings with the highest peripheral neuropathy burden [42]. As peripheral 
neuropathy is typically chronic, and ART and/or TB treatment is needed for other aspects of health, focusing on self-management strategies to control response to pain is essential [43]. There is an analogy with cancer, wherein chemotherapy-induced peripheral neuropathy is viewed by some as an acceptable consequence of successful cancer therapy, which nevertheless also needs long-term selfmanagement strategies that could be translated into HIV infection $[21,44]$.

One limitation of our study is that we assessed peripheral neuropathy only on the basis of clinical diagnosis. Patients were asked at each 12-weekly visit of any symptoms consistent with peripheral neuropathy, which were then graded by the doctor taking into consideration other causes based on a physical examination conducted at each visit; thus, our outcome is based on self-report in contrast to other studies such as the BPNS used in Mehta et al. [11], which incorporated objective measures as well as reported symptoms. Estimates of prevalence and incidence will depend on the criteria used to define peripheral neuropathy; nevertheless, the fact that we found the expected predictors of pre-ART age, weight and stavudine use suggests that this outcome was reasonably well ascertained. The majority (94\%) of peripheral neuropathy events reported were grade $1 / 2$; it is possible that on the basis of our simple clinical criteria, some cases with mild symptoms were missed, but it is unlikely that many severe cases were not included. We were unable to definitively identify whether peripheral neuropathy risks differ significantly between isoniazid with pyridoxine and isoniazid without pyridoxine; although it is possible that some patients were given pyridoxine without this being recorded, all concomitant medications were requested on trial CRFs, and point estimates suggested that isoniazid-associated peripheral neuropathy risk could be substantially reduced by adding pyridoxine. Nonadherence to ART may also increase the risk of peripheral neuropathy, and conversely, peripheral neuropathy could have adverse effects on adherence and/ or quality of life. These factors may have compounded the risk of peripheral neuropathy, but are difficult to adequately disentangle. However, despite the limitations, our findings are consistent with more recent studies, and are also on a very large $(\sim 3000)$ cohort, with very long $(\sim 5$ year) follow-up. In contrast, previous studies from resource-limited settings were mainly cross-sectional in nature or had short follow-up and/or individuals initiated ART exclusively with stavudine.

\section{Conclusion}

Isoniazid, stavudine and didanosine increase the incidence of peripheral neuropathy, independently of preART age and weight. Of note, among those taking isoniazid, we were unable to show definitively that the risk of peripheral neuropathy was lower in those who also took pyridoxine versus those who did not; and we did not find any evidence of increased risk in women or according to pre-ART or current $\mathrm{CD} 4^{+}$cell count in contrast to previous studies. Our study highlights that screening for peripheral neuropathy may be important in in older participants and those with higher BMI initiating ART. Although didanosine is no longer recommended by WHO for second-line, it is still being used in some patients; other second-line drugs might be preferable in higher risk patients, particularly if receiving isoniazid for treatment or as prophylaxis. The more frequent occurrence of HIV and TB coinfection in sub-Saharan Africa may require further consideration in screening for peripheral neuropathy.

\section{Acknowledgements}

We thank all the patients and staff from all the centres participating in the DART trial.

MRC/UVRI Uganda Research Unit on AIDS, Entebbe, Uganda: H. Grosskurth, P. Munderi, G. Kabuye, D. Nsibambi, R. Kasirye, E. Zalwango, M. Nakazibwe, B. Kikaire, G. Nassuna, R. Massa, K. Fadhiru, M. Namyalo, A. Zalwango, L. Generous, P. Khauka, N. Rutikarayo, W. Nakahima, A. Mugisha, J. Todd, J. Levin, S. Muyingo, A. Ruberantwari, P. Kaleebu, D. Yirrell, N. Ndembi, F. Lyagoba, P. Hughes, M. Aber, A. Medina Lara, S. Foster, J. Amurwon, B. Nyanzi Wakholi, K. Wangati, B. Amuron, D. Kajungu, J. Nakiyingi, W. Omony, K. Fadhiru, D. Nsibambi, P. Khauka.

Joint Clinical Research Centre, Kampala, Uganda: P. Mugyenyi, C. Kityo, F. Ssali, D. Tumukunde, T. Otim, J. Kabanda, H. Musana, J. Akao, H. Kyomugisha, A. Byamukama, J. Sabiiti, J. Komugyena, P. Wavamunno, S. Mukiibi, A. Drasiku, R. Byaruhanga, O. Labeja, P. Katundu, S. Tugume, P. Awio, A. Namazzi, G.T. Bakeinyaga, H. Katabira, D. Abaine, J. Tukamushaba, W. Anywar, W. Ojiambo, E. Angweng, S. Murungi, W. Haguma, S. Atwiine, J. Kigozi, L. Namale, A. Mukose, G. Mulindwa, D. Atwiine, A. Muhwezi, E. Nimwesiga,

G. Barungi, J. Takubwa, S. Murungi, D. Mwebesa, G. Kagina, M. Mulindwa, F. Ahimbisibwe, P. Mwesigwa, S. Akuma, C. Zawedde, D. Nyiraguhirwa, C. Tumusiime, L. Bagaya, W. Namara, J. Kigozi, J. Karungi, R. Kankunda, R. Enzama.

University of Zimbabwe, Harare, Zimbabwe: A Latif, J Hakim, V Robertson, A Reid, E Chidziva, R BulayaTembo, G Musoro, F Taziwa, C Chimbetete, L Chakonza, A Mawora, C Muvirimi, G Tinago, P Svovanapasis, M Simango, O Chirema, J Machingura, S Mutsai, M Phiri, T Bafana, M Chirara, L Muchabaiwa, M Muzambi, E Chigwedere, M Pascoe, C Warambwa, E Zengeza, F Mapinge, S Makota, A Jamu, N Ngorima, H Chirairo, S Chitsungo, J Chimanzi, C Maweni, RWarara, 
M Matongo, S Mudzingwa, M Jangano, K Moyo, L Vere, I Machingura.

Infectious Diseases Institute (formerly the Academic Alliance) Makerere University, Mulago, Uganda: E Katabira, A Ronald, A Kambungu, F Lutwama, I Mambule, A Nanfuka, J Walusimbi, E Nabankema, R Nalumenya, T Namuli, R Kulume, I Namata, L Nyachwo, A Florence, A Kusiima, E Lubwama, R Nairuba, F Oketta, E Buluma, R Waita, H Ojiambo, F Sadik, J Wanyama, P Nabongo, J Oyugi, F Sematala, A Muganzi, C Twijukye, H Byakwaga.

The AIDS Support Organisation (TASO), Uganda: R. Ochai, D. Muhweezi, A. Coutinho, B. Etukoit.

Imperial College, London, UK: C Gilks, K Boocock, C Puddephatt, C Grundy, J Bohannon, D Winogron. MRC Clinical Trials Unit, London, UK: J Darbyshire, DM Gibb, A Burke, D Bray, A Babiker, AS Walker, H Wilkes, M Rauchenberger, S Sheehan, C Spencer-Drake, K Taylor, M Spyer, A Ferrier, B Naidoo, D Dunn, R Goodall.

Independent DART Trial Monitors: R. Nanfuka, C. Mufuka-Kapuya.

DART Virology Group: P Kaleebu (Co-Chair), D Pillay (Co-Chair), V Robertson, D Yirrell, S Tugume, M Chirara, P Katundu, N Ndembi, F Lyagoba, D Dunn, R Goodall, A McCormick.

DART Health Economics Group: A Medina Lara (Chair), S Foster, J Amurwon, B Nyanzi Wakholi, J Kigozi, L Muchabaiwa, M Muzambi.

Trial Steering Committee: I Weller (Chair), A Babiker (Trial Statistician), S Bahendeka, M Bassett, A Chogo Wapakhabulo, J Darbyshire, B Gazzard, C Gilks, H Grosskurth, J Hakim, A Latif, C Mapuchere, O Mugurungi, P Mugyenyi; Observers: Mounir AitKhaled, C Burke, M Distel, S Jones, E Loeliger, P Naidoo, C Newland, G Pearce, S Rahim, J Rooney, M Smith, W Snowden, J-M Steens, M Ait-Khaled.

Data and Safety Monitoring Committee: A Breckenridge (Chair), A McLaren (Chair-deceased), C Hill, J Matenga, A Pozniak, D Serwadda.

Endpoint Review Committee: T. Peto (Chair), A. Palfreeman, M. Borok, E. Katabira.

DARTwas funded by the UK Medical Research Council, the UK Department for International Development (DFID) and the Rockefeller Foundation. GlaxoSmithKline, Gilead and Boehringer-Ingelheim donated first-line drugs for DART, and Abbott provided LPV/r (Kaletra/ Aluvia) as part of the second-line regimen for DART.
This work was supported by the United Kingdom (UK) Medical Research Council [grant number G0600344], the DFID and the Rockefeller Foundation. GlaxoSmithKline/ViiV, Gilead Sciences, Boehringer-Ingelheim and AbbVie Ltd donated drugs for DART. The funders had no role in study design, data collection and analysis, decision to publish or preparation of the manuscript.

S.K.M., A.S.W. C.F.G. and J.L. designed the study. I.M., B.K., H.M. and G.M. collected data. S.K.M., A.S.W. did the analyses and wrote the first draft together with J.L. All authors contributed to interpretation of the data, reviewed the manuscript critically and approved the final version.

\section{Conflicts of interest}

There are no conflicts of interest.

\section{References}

1. So YT, Holtzman DM, Abrams DI, Olney RK. Peripheral neuropathy associated with acquired immunodeficiency syndrome. Prevalence and clinical features from a population-based survey. Arch Neurol 1988; 45:945-948.

2. Schifitto G, McDermott MP, McArthur JC, Marder K, Sacktor N Epstein L, et al. Incidence of and risk factors for HIV-associated distal sensory polyneuropathy. Neurology 2002; 58:1764-1768.

3. Moore RD, Wong WM, Keruly JC, McArthur JC. Incidence of neuropathy in HIV-infected patients on monotherapy versus those on combination therapy with didanosine, stavudine and hydroxyurea. AIDS 2000; 14:273-278.

4. Maritz J, Benatar M, Dave JA, Harrison TB, Badri M, Levitt NS, et al. HIV neuropathy in South Africans: frequency, characteristics, and risk factors. Muscle Nerve 2010; 41:599-606.

5. Cherry CL, Skolasky RL, Lal L, Creighton I, Hauer P, Raman SP, et al. Antiretroviral use and other risks for HIV-associated neuropathies in an international cohort. Neurology 2006; 66:867-873.

6. Childs EA, Lyles RH, Selnes OA, Chen B, Miller EN, Cohen BA, et al. Plasma viral load and CD4 lymphocytes predict HIVassociated dementia and sensory neuropathy. Neurology 1999; 52:607-613.

7. Mullin S, Temu A, Kalluvya S, Grant A, Manji H. High prevalence of distal sensory polyneuropathy in antiretroviraltreated and untreated people with HIV in Tanzania. Trop Med Int Health 2011; 16:1291-1296.

8. Monroe A. Understanding and managing peripheral neuropathy. BETA 2010; 22:27-35.

9. Beadles WI, Jahn A, Weigel R, Clutterbuck D. Peripheral neuropathy in HIV-positive patients at an antiretroviral clinic in Lilongwe, Malawi. Trop Doct 2009; 39:78-80.

10. Wadley AL, Cherry CL, Price P, Kamerman PR. HIV neuropathy risk factors and symptom characterization in stavudineexposed South Africans. I Pain Symptom Manage 2011; 41:700-706.

11. Mehta SA, Ahmed A, Kariuki BW, Said S, Omasete F, Mendillo $M$, et al. Implementation of a validated peripheral neuropathy screening tool in patients receiving antiretroviral therapy in Mombasa, Kenya. Am J Trop Med Hyg 2010; 83:565-570.

12. Robertson K, Kumwenda J, Supparatpinyo K, Jiang JH, Evans S, Campbell $\mathrm{TB}$, et al. A multinational study of neurological performance in antiretroviral therapy-naive HIV-1-infected persons in diverse resource-constrained settings. / Neurovirol 2011; 17:438-447.

13. Luma HN, Tchaleu BC, Doualla MS, Temfack E, Sopouassi VN, Mapoure $\mathrm{YN}$, et al. HIV-associated sensory neuropathy in HIV-1 infected patients at the Douala General Hospital in Cameroon: a cross-sectional study. AIDS Res Ther 2012; 9:35. 
14. Evans D, Takuva S, Rassool M, Firnhaber C, Maskew M. Prevalence of peripheral neuropathy in antiretroviral therapy naive HIV-positive patients and the impact on treatment outcomes - a retrospective study from a large urban cohort in Johannesburg, South Africa. / Neurovirol 2012; 18:162-171.

15. Ghosh S, Chandran A, Jansen JP. Epidemiology of HIV-related neuropathy: a systematic literature review. AIDS Res Hum Retroviruses 2012; 28:36-48.

16. Mugyenyi P, Walker AS, Hakim J, Munderi P, Gibb DM, Kityo C, et al. Routine versus clinically driven laboratory monitoring of HIV antiretroviral therapy in Africa (DART): a randomised noninferiority trial. Lancet 2010; 375:123-131.

17. WHO. World Health Organization scaling up antiviral therapy in resource limited settings: guidelines for a public health approach. Geneva, Switzerland: WHO; 2002.

18. DART Trial Team. Fixed duration interruptions are inferior to continuous treatment in African adults starting therapy with CD4 cell counts $<\mathbf{2 0 0}$ cells/microl. AIDS 2008; 22:237-247.

19. Royston P, Ambler G, Sauerbrei W. The use of fractional polynomials to model continuous risk variables in epidemiology. Int J Epidemiol 1999; 28:964-974.

20. Van der Watt JJ, Harrison TB, Benatar M, Heckmann JM. Polyneuropathy, antituberculosis treatment and the role of pyridoxine in the HIV/AIDS era: a systematic review. Int J Tuberc Lung 2011; 15:722-728.

21. Tofthagen C, Visovsky CM, Hopgood R. Chemotherapy-induced peripheral neuropathy: an algorithm to guide nursing management. Clin J Oncol Nurs 2013; 17:138-144.

22. McGrath CJ, Njoroge J, John-Stewart GC, Kohler PK, BenkiNugent SF, Thiga JW, et al. Increased incidence of symptomatic peripheral neuropathy among adults receiving stavudineversus zidovudine-based antiretroviral regimens in Kenya. J Neurovirol 2012; 18:200-204.

23. Menezes CN, Maskew M, Sanne I, Crowther NJ, Raal FJ. A longitudinal study of stavudine-associated toxicities in a large cohort of South African HIV infected subjects. BMC Infect Dis 2011; 11:244.

24. Lichtenstein KA, Armon C, Baron A, Moorman AC, Wood KC, Holmberg SD. Modification of the incidence of drug-associated symmetrical peripheral neuropathy by host and disease factors in the HIV outpatient study cohort. Clin Infect Dis 2005; 40:148-157.

25. Kelleher T, Cross A, Dunkle L. Relation of peripheral neuropathy to HIV treatment in four randomized clinical trials including didanosine. Clin Ther 1999; 21:1182-1192.

26. Nicholas PK, Kemppainen JK, Holzemer WL, Nokes KM, Eller LS, Corless IB, et al. Self-care management for neuropathy in HIV disease. AIDS Care 2002; 14:763-771.

27. Sithinamsuwan $P$, Punthanamongkol S, Valcour V, Onsanit S, Nidhinandana $S$, Thitivichianlert $S$, et al. Frequency and characteristics of HIV-associated sensory neuropathy among HIV patients in Bangkok, Thailand. I Acquir Immune Defic Syndr 2008; 49:456-458.

28. Shurie JS, Deribew A. Assessment of the prevalence of distal symmetrical polyneuropathy and its risk factors among HAART-treated and untreated HIV infected individuals. Ethiop Med / 2010; 48:85-93.

29. WHO. Consolidated guidelines on the use of antiretroviral drugs for treating and preventing HIV infection. Geneva, Switzerland: World Health Organisation; 2013.
30. Arenas-Pinto A, Bhaskaran K, Dunn D, Weller IV. The risk of developing peripheral neuropathy induced by nucleoside reverse transcriptase inhibitors decreases over time: evidence from the Delta trial. Antiviral Ther 2008; 13:289-295.

31. Lichtenstein KA, Armon C, Buchacz K, Chmiel JS, Moorman AC, Wood KC, et al. Initiation of antiretroviral therapy at CD4 cell counts $>/=350$ cells $/ \mathrm{mm} 3$ does not increase incidence or risk of peripheral neuropathy, anemia, or renal insufficiency. J Acquir Immune Defic Syndr 2008; 47:27-35.

32. Pahuja M, Grobler A, Glesby MJ, Karim F, Parker G, Gumede S, et al. Effects of a reduced dose of stavudine on the incidence and severity of peripheral neuropathy in HIV-infected adults in South Africa. Antiviral Ther 2012; 17:737-743.

33. Mehta SA, Ahmed A, Laverty M, Holzman RS, Valentine F, Sivapalasingam $S$. Sex differences in the incidence of peripheral neuropathy among Kenyans initiating antiretroviral therapy. Clin Infect Dis 2011; 53:490-496.

34. Lopez OL, Becker JT, Dew MA, Caldararo R. Risk modifiers for peripheral sensory neuropathy in HIV infection/AIDS. Eur J Neurol 2004; 11:97-102.

35. Oshinaike O, Akinbami A, Ojo O, Ogbera A, Okubadejo $N$, Ojini $\mathrm{F}$, et al. Influence of age and neurotoxic HAART use on frequency of HIV sensory neuropathy. AIDS Res Treat 2012; 2012:961510.

36. Zingmond DS, Kilbourne AM, Justice AC, Wenger NS, Rodriguez-Barradas $M$, Rabeneck $L$, et al. Differences in symptom expression in older HIV-positive patients: the Veterans Aging Cohort 3 Site Study and HIV Cost and Service Utilization Study experience. J Acquir Immune Defic Syndr 2003; 33 (Suppl 2): S84-S92.

37. Cherry CL, Affandi JS, Imran D, Yunihastuti E, Smyth K, Vanar S, et al. Age and height predict neuropathy risk in patients with HIV prescribed stavudine. Neurology 2009; 73:315-320.

38. van Griensven I, Zachariah R, Rasschaert F, Mugabo J, Atte EF, Reid T. Stavudine- and nevirapine-related drug toxicity while on generic fixed-dose antiretroviral treatment: incidence, timing and risk factors in a three-year cohort in Kigali, Rwanda. Trans R Soc Trop Med Hyg 2010; 104:148-153.

39. Affandi JS, Price P, Imran D, Yunihastuti E, Djauzi S, Cherry CL. Can we predict neuropathy risk before stavudine prescription in a resource-limited setting? AIDS Res Hum Retroviruses 2008; 24:1281-1284.

40. Ofotokun I, Pomeroy C. Sex differences in adverse reactions to antiretroviral drugs. Topics HIV Med 2003; 11:55-59.

41. Currier JS, Spino C, Grimes J, Wofsy CB, Katzenstein DA Hughes MD, et al. Differences between women and men in adverse events and $\mathrm{CD4}+$ responses to nucleoside analogue therapy for HIV infection. The Aids Clinical Trials Group 175 Team. J Acquir Immune Defic Syndr 2000; 24:316-324.

42. Youle M, Osio M. A double-blind, parallel-group, placebocontrolled, multicentre study of acetyl L-carnitine in the symptomatic treatment of antiretroviral toxic neuropathy in patients with HIV-1 infection. HIV Med 2007; 8:241-250.

43. Nicholas PK, Voss J, Wantland D, Lindgren T, Huang E, Holzemer $\mathrm{WL}$, et al. Prevalence, self-care behaviors, and self-care activities for peripheral neuropathy symptoms of HIV/AIDS. Nurs Health Sci 2010; 12:119-126.

44. Tofthagen C, Gonzalez L, Visovsky C, Akers A. Self-management of oxaliplatin-related peripheral neuropathy in colorectal cancer survivors. Chemother Res Pract 2013; 2013:547932. 